\title{
Designing of Fuzzy Logic Controller for Liquid Level Controlling
}

\author{
Ashish Singh Thakur, Himmat Singh and Sulochana Wadhwani \\ Department of Electrical Engineering \\ Madhav Institute of Technology \& Science, Gwalior, India \\ e-mail: ashish05singh1990@gmail.com,himmatmind100@yahoo.com, \\ sulochana_wadhwanil@rediffmail.com
}

\begin{abstract}
In control system there are a number of general systems and methods which are encountered in all areas of industry and technology. There are many ways to control any system, in which fuzzy is often the very best way. The only reason is faster and cheaper. One of successful application that is used for the controlling of liquid level is fuzzy logic controller. In order to find the best design to stabilize the liquid level in this method, some factors will be considered. For this paper, the liquid level was controlled by using three rules of membership function which then extended to five rules, seven rules and nine rules for verification purpose and further improvement of the system. This paper was focused to the software part only. By doing some modification in this paper, the design will be very useful for the system relates to liquid level control that widely use in industry nowadays. For a long time, the selection and definition of the parameters of PID controller are very difficult. There must be a bad effect if you do not choose nicely parameters. To strictly limit the overshoot, the use of Fuzzy controller can achieve a great control cause. In this paper, we take the liquid level water tank, and use MATLAB to design a Fuzzy Controller. Then we analyze the control effect and compare it with the effect of PID controller. As a result of comparing, Fuzzy Logic Controller is superior to PID controller. Comparison of the control results from these two systems indicated that the Fuzzy logic controller significantly reduced overshoot and steady state error.
\end{abstract}

Keywords: PID Controller, Fuzzy Logic Controller, Rule Viewer, FIS, Graphical User Interface, Liquid Level System, MATLAB Simulation

\section{Introduction}

Traditionally, accurate mathematical model-based strategy has been applied to deal with control problems. However, liquid level control system is very complex system. Conventional control approaches are convenient to solve these difficulties. Level control is one of the most important aspects widely used in industrial process control. It got a wide range of applications like in nuclear power plants, chemical industries, etc. As the parameters of the plant changes frequently, maintaining the water level at its set point value is difficult. Hence, it is required to design a controller which controls the level of the liquid at its set point value and also it must accept the variable disturbances on the plant. PID controller is the earliest used controller in the industries [1]. But it is difficult to get the efficient control because the PID gains setting is a challenging task. It is hard to control nonlinear processes with linear classic controllers. If the nonlinear process working point changes all the conventional controller parameters must be modified in order to keep the control performance. An interesting approach fuzzy logic controller is used to control nonlinear processes [2].

Applying fuzzy logic in the designing of the fuzzy logic controllers the control knowledge of the operators can be used to obtain the necessary fuzzy rule bases in the 
control strategies. The fuzzy rule bases consist of linguistic rules that give full details of the Fuzzy Logic Controllers actions to achieve good performances for the controlled nonlinear processes. To implement a fuzzy logic controller a fuzzy inference reasoning method must be used to activate the fuzzy rule base. The sensory data from process go to the Fuzzy Logic Controller input through an analog digital interface and then through a fuzzification block that converts the crisp numerical data into fuzzy data. These fuzzy data fire some rules from Fuzzy Logic Controller rule base and from each fired rule a value of a fuzzy control output is obtained. The final fuzzy control output is computed applying a fuzzy inference reasoning method over all simultaneously fuzzy control output obtained from the fired rules. Then the final fuzzy control outputs go through a defuzzification block to be converted from fuzzy to crisp numerical signals and through a digital - analog interface to be converted into an analogue control signal [3]. The Fuzzy Logic Controller must contain a number of set of parameters that can be altered to modify the controller performance. These parameters are: - the scaling factors for each variable; the fuzzy set representing the meaning of linguistic values; the fuzzy rules. For a successfully work the number of parameters to be tuned should be as small as possible [4]. This paper presents a practical method to achieve Fuzzy Logic Controllers with decision tables that can be used to solve the control problems in the real time industrial applications.

\section{Liquid-tank System}

Liquid is flowing into a tank at some rate water in $(\mathrm{Q}$ in $)$ and out of the tank at some rate water out $\left(\mathrm{Q}_{\text {out }}\right)$. The liquid in the tank at some height or level $\mathrm{H}$ it is known as output flow rate varies as the square root of the height $\mathrm{Q}_{\text {out }}=\mathrm{a} \sqrt{H}$, so the higher the level, faster the water flow out. If the output flow rate is not accurately equal to input flow rate, the level will drop, $\left(\mathrm{Q}_{\text {out }}>\mathrm{Q}_{\text {in }}\right)$ or rise, if $\left(\mathrm{Q}_{\text {out }}<\mathrm{Q}_{\text {in }}\right)$ [5]. This process has a property called self-regulation. This means that at some input water flow rate, the water height will rise until it reaches a height for which the output flow rate matches the input flow rate.

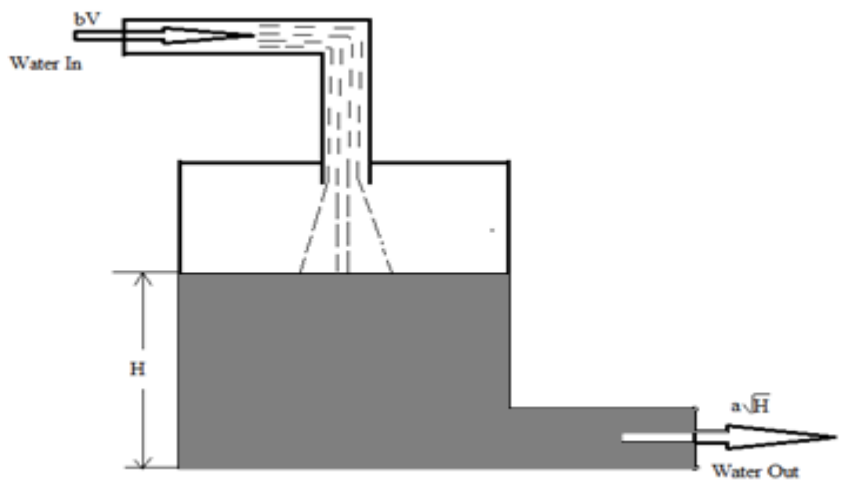

Figure 1. Schematic Diagram for Liquid-Tank System

A self-regulating system does not provide regulation of a variable to any particular reference value. In this example, the liquid level will accept some value for which input and output flow rate are the same, and there it will stay. But if the input flow rate changed, then the level would modify also. So it is not synchronized to a reference value. Suppose we want to keep the level at some particular value ' $H$ ' in Figure 1 regardless of the input flow rate then something more than self-regulation is needed. Water enters a tank from the top and leaves through an orifice in its base. The rate that water enters is directly proportional to the voltage, $\mathrm{V}$, applied to the pump. The rate at which water leaves is directly proportional to the square root of the height of water in the tank. 


\section{A. Model Equation}

The equation for the height of liquid in the tank ' $\mathrm{H}$ ' is given by

$$
\frac{d}{d t} V=A \frac{d H}{d t}=b V-a \sqrt{H}
$$

Water-Tank System Block is given as

$$
\dot{V}=\frac{A}{b} \dot{H}=V-\frac{a}{b} \sqrt{H}
$$

Where ' $\mathrm{V}$ ': volume of liquid in the tank, ' $\mathrm{A}$ ': cross-sectional area of the tank, ' $b$ ': constant related to the flow rate into the tank and ' $a$ ': constant related to the flow rate out of the tank. The values of the parameters are specified as $a=2 \mathrm{~cm} 2.5 / \mathrm{s}, \mathrm{A}=20 \mathrm{~cm} 2, \mathrm{~b}=5$ $\mathrm{cm}^{3}$. The equation describes the water height, $\mathrm{H}$, as a function of time, due to the difference between flows rates into and out of the tank. It is nonlinear due to its dependence on the square-root of ' $\mathrm{H}$ '. Linearizing the model, using Simulation Control Design, simplifies the analysis of this model [6].

The level is sensed by a suitable sensor and converted to a signal acceptable to the controller. The controller compares the level indicator to the preferred set-point temperature and actuates the control element. The control element alters the manipulated variable to change position of the valve so that the quantity of liquid being added can be controlled in the process. The purpose of the controller is to regulate the level as close to the set point as possible.

\section{B. Working of Liquid Level}

A continuous square wave is applied at current to pressure converter to the controller for creating continuous disturbance. Another current to pressure converter of the controller comes from feedback. The controller acts according to the error generated. This error and its derivative is useful for the controller which then takes the necessary action and decides the location of the valve which gives the desired flow of the water into the tank. The position of the valve is decided by PID Controller or by the rules written in the Fuzzy Logic Controller Rule Editor. If the water level in the tank is low then the valve open completely and if the water level is high in the tank then the valve closes or opens up to a point. When the level is full then the valve is fully closed. The PID controller can be changed by varying the values of Proportional Gain, Integral Gain \& Derivative Gain and effect of the changed values can be seen effectively using rule viewer.

\section{Designing of Fuzzy Logic Controller}

\section{A. FIS Editor}

We have defined two Inputs for the Fuzzy Controller. One is level of the water in the tank denoted as "Level" and the other one is rate of change of water in the tank denoted as "Rate". Both these Inputs are applied to the Rule Editor [7]. According to the Rules written in the Rule Editor the controller takes the action and gives the opening of the Valve which is the output of the controller and is denoted by "Valve".

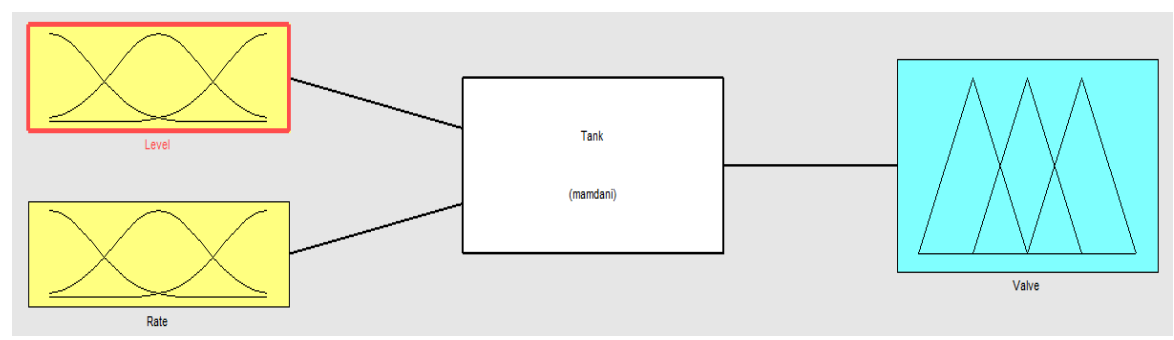

Figure 2. Mamdani Type Fuzzy Controller 


\section{B. Membership Function Editor}

The Membership Function Editor shares some features with the FIS Editor. In fact, all of the five basic graphical user interface tools have similar menu options. The MF Editor is the tool that let you display and edits all of the membership functions associated with all of the input and output variables for the entire fuzzy inference system [8-9]. When you open the Membership Function Editor to work on a fuzzy inference system that does not already exist in the workspace, there is not yet any membership functions associated with the variables that you have just defined with the FIS Editor.

a) Fuzzy Set Characterizing Input

i. Level [Range (-10 to 10)]

Table I. Crisp Range Table for Level

\begin{tabular}{|c|c|c|}
\hline Fuzzy Variable & MF Used & $\begin{array}{c}\text { Crisp Input } \\
\text { Range }\end{array}$ \\
\hline Negative & Triangular MF & $\left(\begin{array}{llll}-18 & -10 & 1\end{array}\right)$ \\
\hline Zero & Triangular MF & $\left(\begin{array}{lll}-8 & 0 & 8\end{array}\right)$ \\
\hline Positive & Triangular MF & $\left(\begin{array}{llll}0 & 10 & 18\end{array}\right)$ \\
\hline
\end{tabular}

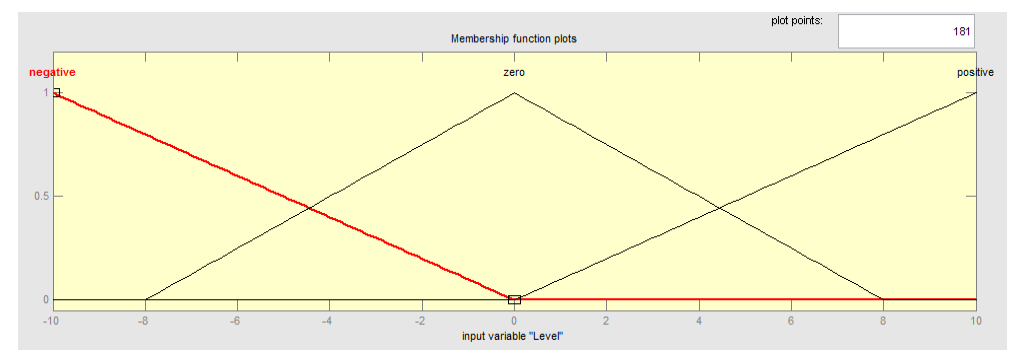

Figure 3. Membership Function Fuzzy Set Characterize Input

ii. Rate [Range (-0.5 to 0.5$)]$

Table II. Crisp Range Table for Rate

\begin{tabular}{|c|c|c|}
\hline Fuzzy Variable & MF Used & $\begin{array}{c}\text { Crisp Input } \\
\text { Range }\end{array}$ \\
\hline Negative & Triangular MF & $(-0.9-0.50)$ \\
\hline Zero & Triangular MF & $\left(\begin{array}{lll}-0.4 & 0 & 0.4\end{array}\right)$ \\
\hline Positive & Triangular MF & $\left(\begin{array}{lll}0 & 0.5 & 0.9\end{array}\right)$ \\
\hline
\end{tabular}

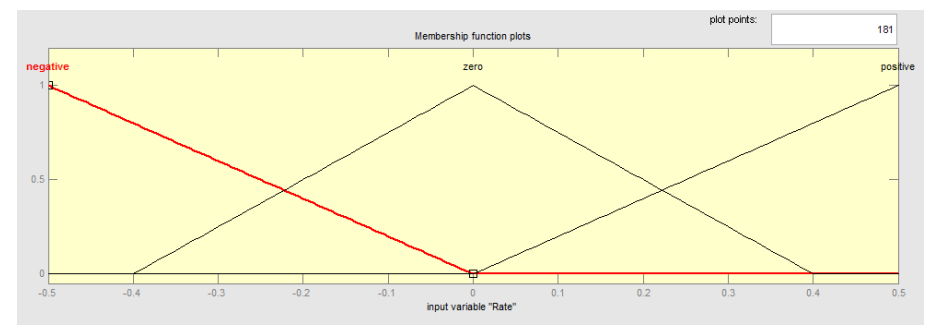

Figure 4. Membership Function Fuzzy Set Characterize Output

b) Fuzzy Set Characterizing Output

Use triangular membership function types for the output. First, set the Range (and the Display Range) to (-5 5), to cover the output range. Initially, the negative membership 
function will have the parameters (-9 -50$)$, the zero membership function will be (-4 04$)$, for the positive membership function will be (0 5 9).

i. $\quad$ Valve [(Range (-5 to 5$)]$

Table III. Crisp Range Table for Valve

\begin{tabular}{|c|c|c|}
\hline Fuzzy Variable & MF Used & Crisp Input Range \\
\hline Negative & Triangular MF & $(-9$-5 0) \\
\hline Zero & Triangular MF & $(-404)$ \\
\hline Positive & Triangular MF & $\left(\begin{array}{ll}0 & 5\end{array}\right)$ \\
\hline
\end{tabular}

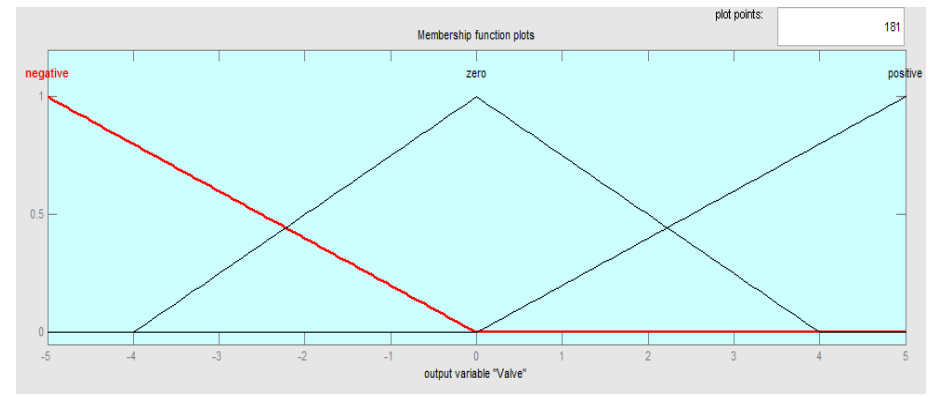

Figure 5. Triangular Membership Function Output

\section{Rule Editor}

Constructing rules using the graphical Rule Editor interface is fairly self-evident. Based on the input and output variables defined with the FIS Editor, the Rule Editor allows you to create the rule statements automatically [10].

1. If (Level is negative) and (Rate is negative) then (Valve is negative) (1).

2. If (Level is negative) and (Rate is zero) then (Valve is negative) (1).

3. If (Level is negative) and (Rate is positive) then (Valve is negative) (1).

4. If (Level is zero) and (Rate is negative) then (Valve is negative) (1).

5. If (Level is zero) and (Rate is zero) then (Valve is zero) (1).

6. If (Level is zero) and (Rate is positive) then (Valve is positive) (1).

7. If (Level is positive) and (Rate is negative) then (Valve is positive) (1).

8. If (Level is positive) and (Rate is zero) then (Valve is positive) (1).

9. If (Level is positive) and (Rate is positive) then (Valve is positive) (1).

\section{Simulation Block Diagram}

A. Valve

The liquid flow level can be controlled by using limited integrator in the simulated valve subsystem is given as

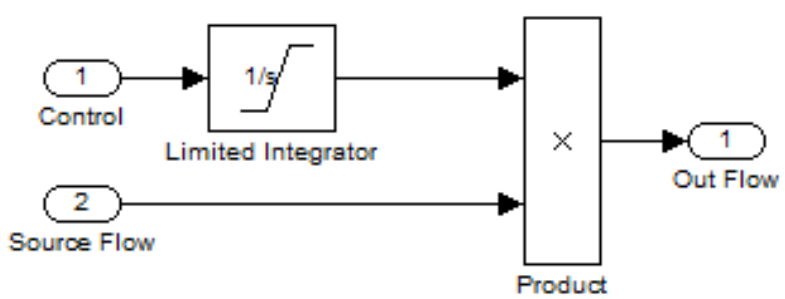

Figure 6. Block Diagram of Valve Subsystem 
B. Water Tank

The simulation block diagram for the water tank is given

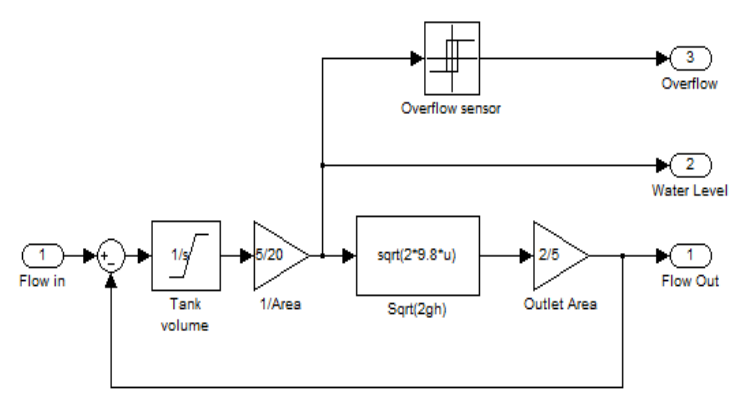

Figure 7. Block Diagram of Water Tank

C. Controller Block

The circuitry for the controller of liquid tank is given as

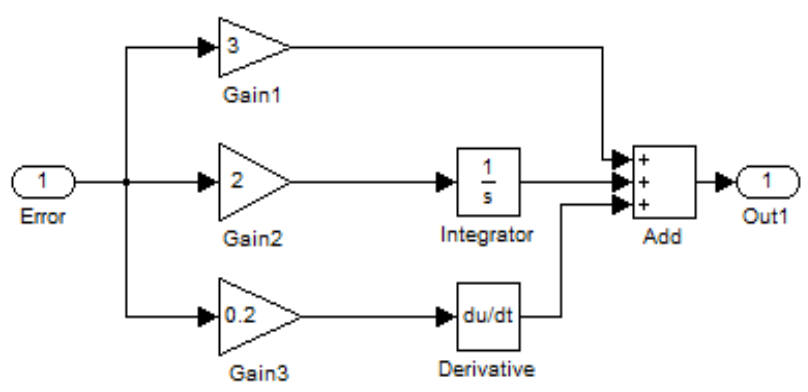

Figure 8. Block Diagram of Pid Controller

The output of the controller governs the opening or closing of the valve [11-13]. The liquid level is sensed by the liquid level sensors and the rate of change is calculated by the derivative of the level signal after that the limits of which are decided by a saturation nonlinearity.

\section{Simulation Model of PID Controller}

Simulation model of Conventional PID Controller for liquid level control as shown in Figure 9. In this we control the water level of the system with the help of PID controller in the MATLAB simulation. Two inputs are given in the valve these are control and source flow with an limited integrator the control valve is connected to the PID controller for controlling the outflow and a constant is connected to the valve source flow for controlling the level the output of valve is given to the water tank at which we observe the liquid flow out, water level and over flow. 


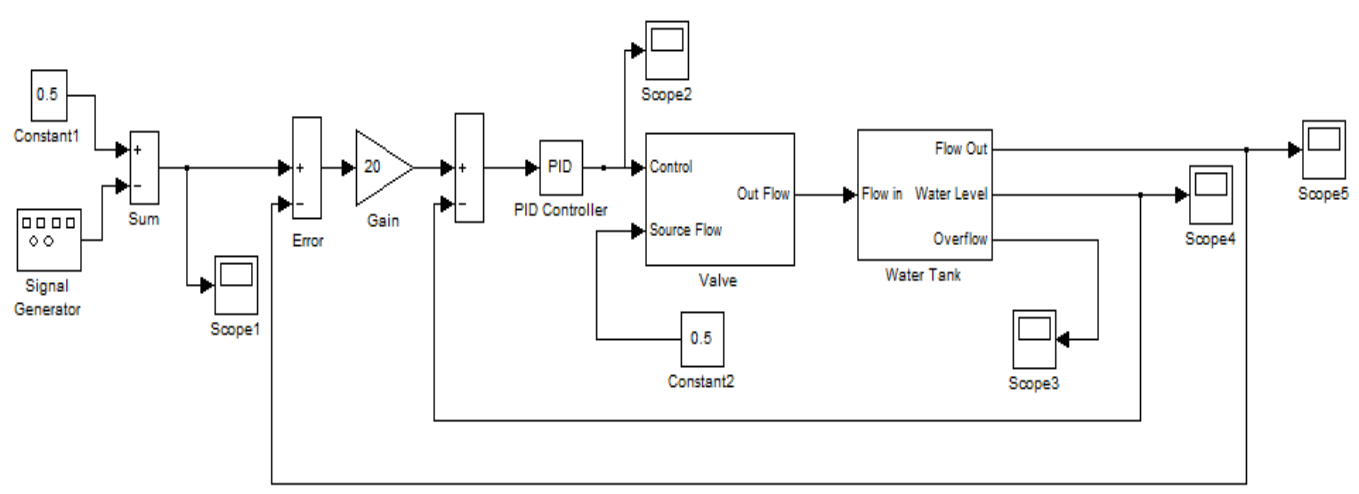

Figure 9. Simulation Model by Using Pid Controller

E. Simulation Model of Fuzzy Logic Controller

A simulation model for Fuzzy Logic Controller for liquid level control

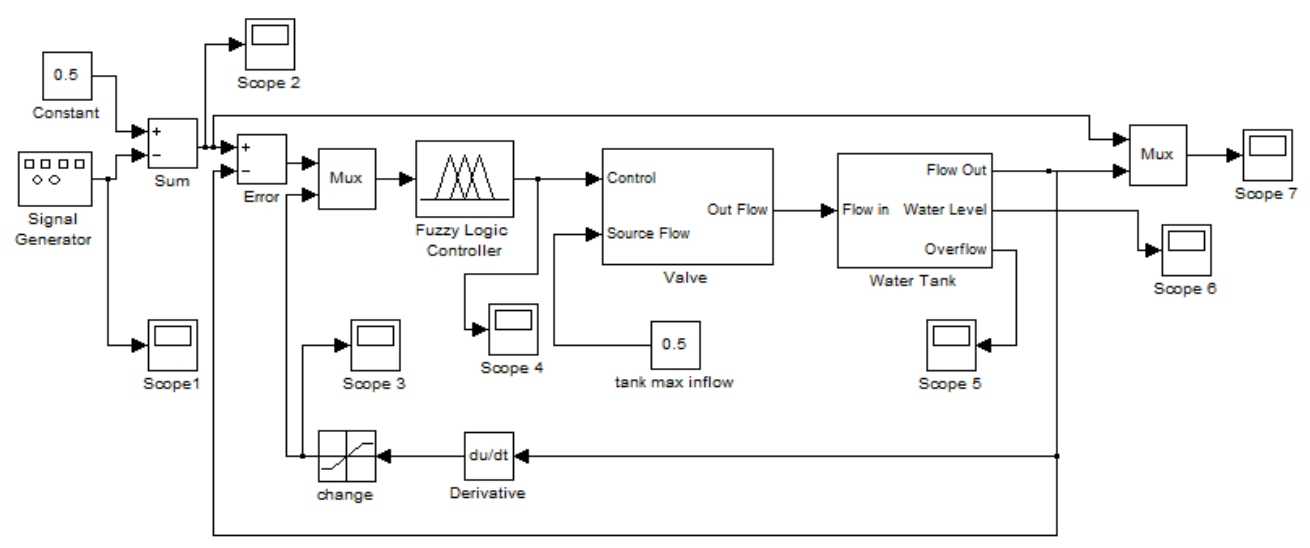

Figure 10. Simulation Model by Using Fuzzy Logic Controller

\section{Simulation Results and Discussion}

A. Simulation Result of PID Controller

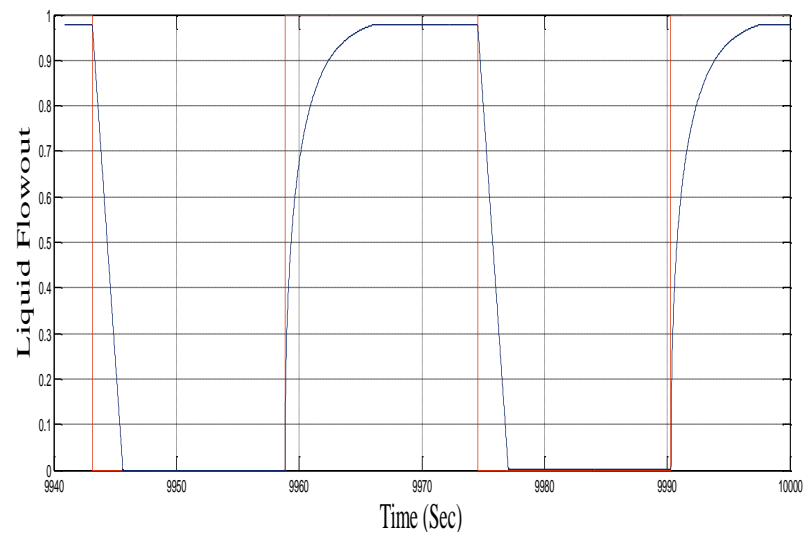

Figure 11. Simulation Result Using Pid Controller 
From Figure 11 it is seen that PID controllers drives the system unstable due to mismatch error generated by the inaccurate time delay parameter used in the plant model. Transient \& overshoot are present when PID controller is used to control the liquid level.

\section{B. Simulation Result of Fuzzy Logic Controller}

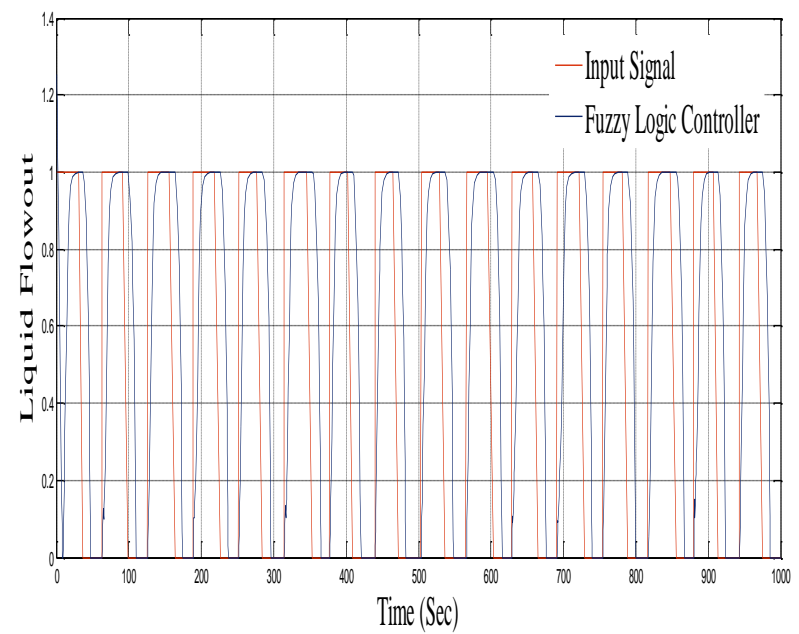

Figure 12. Simulation Result Using Fuzzy Logic Controller

From Figure 12 Fuzzy Logic Controller provide good performance in terms of oscillations and overshoot in the absence of a prediction mechanism. The FLC algorithm adapts rapidly to longer time delays and provides a stable Response.

\section{Discussion}

From Figure 11 it is seen that PID controllers drives the system unstable due to mismatch error generated by the inaccurate time delay parameter used in the plant model. Transients \& overshoots are present when PID controller is used to control the liquid level. It is also clear that with the use of PID controller some steady state error is present in the simulation result. The Fuzzy Logic Controller is applied to the plant described above in Figure 10. Fuzzy Logic Controller simulation results are plotted against with that of conventional controller PID controller for comparison purposes. The simulation results are obtained using a 9 Fuzzy Logic Controller rules.

From the simulations, in the presence of unknown or possibly varying time delay, the proposed Fuzzy Logic Controller shows a significant improvement in maintaining performance and preserving stability over standard PID method. To strictly limit the overshoot, using Fuzzy Controller can achieve a great control effect. Especially it can give more attention to various parameters, such as the response time, the error of steadying and overshoot. Comparison of these two systems indicated that the fuzzy logic controller significantly reduced overshoot and steady state error. Comparison results of PID and FLC are shown in Table IV. The overall performance may be summarized as

Table IV. Comparison Table of Pid \& FIc

\begin{tabular}{|c|c|c|}
\hline Parameters & PID Controller & $\begin{array}{c}\text { Fuzzy Logic } \\
\text { Controller }\end{array}$ \\
\hline Settling Time & More & Less \\
\hline Transient & Present & Not Present \\
\hline Rise Time & Less & More \\
\hline
\end{tabular}




\begin{tabular}{|c|c|c|}
\hline $\begin{array}{c}\text { Steady State } \\
\text { Error }\end{array}$ & Present & Not Present \\
\hline
\end{tabular}

\section{Conclusion}

Unlike the conventional PID controller the Fuzzy Logic Controller has benefits on the system response, a unique Fuzzy Logic Controller using a small number of rules and straightforward implementation has been proposed to solve a class of level control problems with unknown dynamics or variable time delays commonly found in industry which cannot we reduced easily with the help of PID controller. Fuzzy Logic Controller is easy to implement than PID controller. Additionally, the Fuzzy Logic Controller can be easily programmed into many currently available industrial process controllers. The Fuzzy Logic Controller on a level control problem with promising results can be applied to an entirely different industrial level controlling apparatus.

\section{Future Work}

As a future work we can develop design a Fuzzy Logic Controller for a couple tanks system as adaptive Fuzzy Logic Controller like PID algorithm, which gives high performance for systems and high intelligence.

\section{References}

[1] "The Control Handbook", CRC Press, (1999).

[2] H. J. Zimmermann, "Fuzzy set theory - and its applications", Springer Verlag, Berlin, (2001).

[3] A. Zilouchian and M. Jamshidi, "Intelligent control systems using soft computing methodologies", CRC Press, New York, (2001)

[4] L. Mastacan, "New methods to improve fuzzy logic controllers performance," Bulletin of the Polytechnic Institute of Iasi - Electrotehnics, Powers, Electronics, LIV (LVIII), vol. 4, (2008), pp. 629634.

[5] Q. Li, Y. Fang, J. Song and J. Wang, "The application of fuzzy control in liquid level system", "IEEE/ICMTMA", vol. 3, (2011) March, pp. 776-778.

[6] Z. Zhi and H. Lisheng, "Performance assessment for the water level control system in steam generator of the nuclear power plant", "IEEE/CCC", (2011) July, pp. 5842-5847.

[7] E. H. Mamdani, "Advances in the linguistic synthesis of fuzzy controllers".

[8] E. H. Mamdani, "Applications of fuzzy logic to approximate reasoning using linguistic synthesis", IEEE Transactions on Computers, vol. 26, no. 12, (1977), pp. 1182-1191.

[9] P. J. King and E. H. Mamdani, "The application of Fuzzy logic control systems to industrial processes," Automated, vol. 11, (1997), pp. 235-212.

[10] A. A. Dharamniwas, V. Redhu and U. Gupta, "Liquid Level Control by using Fuzzy Logic Controller", International Journal of Advances in Engineering \& Technology, vol. 4, Issue 1, (2012) July, pp. 537549.

[11] Fuzzy Reasoning \& Application - by Yager - Wiley International.

[12] Fuzzy System Theory \& Application - T. Tarano, Asai \& M. Sugeno - Academic Press.

[13] Mc. Neill, F. Martin and T. Allen, "Fuzzy Logic (A Practical Approach)", Academic Press. International Journal of Man Machine Studies, vol. 8, (1976), pp. 669-678. 
International Journal of $u-$ and $e^{-}$Service, Science and Technology Vol.8, No. 6 (2015) 